\title{
Original Article (short paper) \\ Evolution of postural alignment in preschool and school phases: A longitudinal study
}

\author{
Mariana Zingari Camargo ${ }^{1 *}$, Márcio Rogério de Oliveira ${ }^{2}$, Dirce Shizuko Fujisawa ${ }^{1}$ \\ ${ }^{1}$ Universidade Estadual de Londrina, UEL, Londrina, PR. Brazil; ${ }^{2}$ Universidade \\ Norte do Paraná, UNOPAR, Londrina, PR, Brazil
}

\begin{abstract}
Aim: To identify postural variations in the positioning of the head, cervical spine and shoulders of children in two phases - preschool and school. Methods: This was a longitudinal study, a convenience sample with 99 children of both genders, in preschool (5-6 years old) and school (8-11 years old) phases. The postural alignment of the head, cervical spine and shoulders was evaluated through computerized photogrammetry and analyzed by SAPo software. Results: Differences were found between preschool and school phases, but only the variables of shoulder angle (SA) and forward head distance (FHD) were significantly different (SA = 32.79 [30.49 - 35.09] and 35.84 [33.53 - 38.15] p $=0.026$, respectively; FHD $=8.40[8.07-8.73]$ and $11.23[10.94-11.52] \mathrm{p}<0.001$, respectively). A positive correlation was obtained between forward head distance and body mass $(r h o=0.597, p<0.001)$. Conclusion: There are changes in head and shoulder alignment between preschool and school phases, with protrusion of shoulders and forward head distance findings in children who have evolved their posture. Therefore, parents should be aware of children's posture, and health and education professionals should be involved in screening and prevention programs.
\end{abstract}

Keywords: child; growth and development; photogrammetry.

\section{Introduction}

Posture can be defined as a set of positions of the different joints of the body in a certain period, the correct posture being considered one in which minimum stress is applied to the joints ${ }^{1}$. The head and shoulders should follow a correct alignment where the acromion and the external auditory meatus are aligned along the same vertical line ${ }^{2}$. The cervical spine in the sagittal plane should be slightly curved forward and the distance between the head and the cervical spine should be evidenced ${ }^{3}$.

Currently, postural change in children is one of the most common health problems of childhood ${ }^{4}$. Thus, a high percentage of cases of children with postural problems gives warning for the need of prevention programs, in view of their early onset ${ }^{4}$. The position of the head, cervical spine and shoulders of children has been the subject of several studies, due to the effects that the combination of daily factors of life can cause, for example: inadequate sitting posture for a long time, mainly during the use of electronics; being overweight; incorrect ways of carrying backpacks; school furniture with dimensions not suitable for body structure; sedentary lifestyle habits ${ }^{5-8}$. Azabagic, Spahic, Pranjic, Mulic ${ }^{8}$ evaluated the posture and daily habits of 1315 schoolchildren, aged 8 to 12 years, and showed that schoolaged children spent practically $95 \%$ of their time in the seated position in school and approximately 1.5 hours sitting at home in front of electronics. In addition, the study by Foehr showed that American children spend more than 60 minutes a day in front of the computer'. In fact, all of these factors can lead to musculoskeletal disorders in children such as developing postural deformities and pain ${ }^{7,8}$.
Most children can stay in the sitting posture with their torso, back and cervical spine flexed or rotated for longer periods and associated with use of heavy backpacks for longer time develops the increase of kyphosis angle in both girls and boys principally in the phase of growth and development (preschool and school) ${ }^{7}$. The association of children and adolescents with this lifestyle and changes in posture habits can present consequences in the present and in the future, since children and adolescents are in the growth and development phase. Therefore, the objective of this study was to characterize the posture of the head, cervical spine and shoulders in the sagittal plane, by means of photogrammetry. This study was conducted on children in two distinct periods, the preschool and school phases, and it sought to verify the postural variations that occurred. We also aimed to investigate differences between the sexes as well as excess weight in the evolution process of posture. The hypothesis was that the posture of the head, cervical spine and shoulders in preschool boys and girls (5-6 years old) is different than in the school phase (8-11 years old).

\section{Methods}

The present study examined postural evolution in a convenience sample taken from the study of Prado, Beresoski, Camargo, Fernandes, Siqueira, Fujisawa ${ }^{10}$. However, in the second stage of the study (4 years after the initial evaluation), some children had moved from their school or city, which resulted in a reduction in the sample size to 99 children. All participants were evaluated from 2011 to 2016, initially at five to six years 
old (pre-school period) and after approximately three years they were reassessed, at that time in the age group of eight to eleven years old (school period). Children who were excluded from the study belonged to one or more of the following categories of students who: were unable to remain in orthostatic position for the examination; had no understanding or no cooperation in the evaluation; presented chronic or acute disease; had undergone recent surgeries that could interfere with posture; presented physical and/or sensorial impairment; presented neurological, musculoskeletal or cardiorespiratory dysfunction and those whose parents did not approve of participation in the study.

The study was developed in 13 municipal schools in Londrina- PR in a random selection of schools (performed by the Secretary of Education based on the availability of the school). However, representation of all areas of coverage of the municipality was sought.

This was a longitudinal study, with approval by the Ethics Committee of the Universidade Estadual de Londrina (Etic No 1.170.330), Londrina, PR (protocol number CAAE 46540815.1.0000.5231). All parents and/or guardians of the children who participated in the study signed a consent form, according to the recommendation of NHC Resolution 466/12 ${ }^{11}$.

\section{Evaluation procedures}

Participants were submitted to the same evaluation at both times: the first one between 2011 and 2013 (preschool), and the second one (school) between 2015 and 2016. All evaluations were performed by physiotherapists properly trained and linked to the research project (the same physiotherapist performed all evaluations). The evaluation was composed of verification of anthropometric measurements, followed by postural evaluation through photogrammetry.

\section{Measurement Protocols}

The children were weighed and measured for height using a digital scale (brand Marte, model LC200, serial number 314136, year 2010 , with maximal capacity of $200 \mathrm{~kg}$ and minimum of $1000 \mathrm{~g}$ ) and a tape measure fixed on the wall, respectively.

To determine the child's nutritional status, body mass index (BMI) was calculated using AnthroPlus software, available free on the WHO website. The software provides references for overweight and obesity by weight, height and BMI. Z Score values less than -2 indicate low weight; between -2 and +1 eutrophy; between +1 and +2 overweight; and over +2 obesity ${ }^{12}$.

The use of photogrammetry as a tool for postural evaluation has been recommended since it is a safe method and it allows large scale studies in the child population ${ }^{13}$. Photogrammetry has been considered a valid method ${ }^{14,15}$ with acceptable reproducibility ${ }^{16-18}$.

The children were positioned in comfortable orthostatism in front of a non-reflective black background, according to requirements of the software used for photo analysis. Images were captured from the right and left side views, with spherical styrofoam markers with a diameter of $1.5 \mathrm{~cm}$ and flexible white plastic rods, stuck by double-sided tape, at anatomic points for posterior analysis of articular angles. The markers for analysis of the angles were fixed in the anatomical points: C7, tragus and acromion.

A digital camera (Samsung, 10.2 mega pixels) was positioned parallel to the floor on an aluminum tripod (Lightweight Tripod,marca VF - WT3510A), at a height of 108 centimeters and $2.50 \mathrm{~m}$ away from the children, in a set place for all participants. The rooms for evaluation provided participant privacy. Data were evaluated through analysis of scanned images using the software SAPo (Postural Analysis Software), which is free and has been developed for image processing and analysis ${ }^{16}$.

Analyses were made of angular and linear measurements in the sagittal plane (Figure 1) and analyzed by a single trained evaluator. Studies have shown good inter and intra observer reliability for evaluation through photogrammetry ${ }^{16,19,20}$. The variables used in the study were:

Sagittal Head Angle (SHA): the axis at the tragus and two lines, one parallel to the floor and the other joining the tragus to the canthus of the eye. The greater the angle, the greater the cervical extension ${ }^{21}$;

_ Cervical Angle (CA): the axis in the spinous process of $\mathrm{C} 7$, which joins the line between the tragus and the spinous process of $\mathrm{C} 7$ with another parallel to the floor. The lower the CA value, the more forward the head is positioned ${ }^{6,21}$;

_ Shoulder Angle (SA): formed by the intersection of the spinous process of $\mathrm{C} 7$ and the acromion with a parallel line on the floor; the position of the shoulders in protraction/retraction was determined ${ }^{21}$;

_ Forward head distance (FHD): calculated between the tragus and the spinous process of $\mathrm{C} 7$. A higher value indicates a forward head position ${ }^{6,13,22}$.

Figure 1.

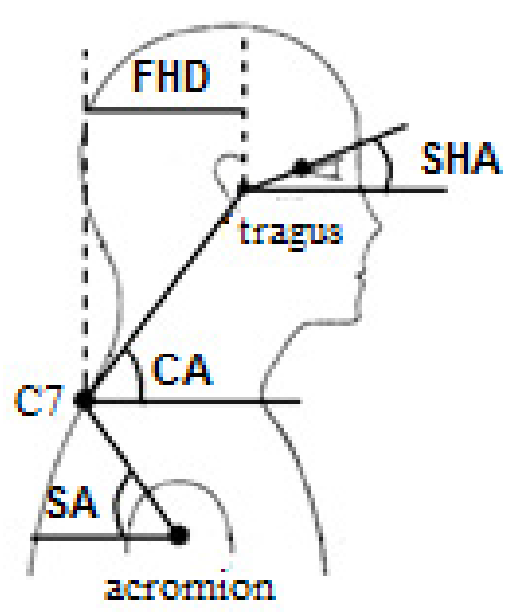

Motriz, Rio Claro, v.23, Special Issue 2, 2017, e101779 


\section{Statistical Analysis}

All statistical analyses were performed using SPSS statistical software (version 20.0 for Windows) with an alpha level of 0.05 . All variables were normally distributed based on the Shapiro-Wilk test. The paired T Student test was used for group comparison (assessment and reassessment). A mixed model $2 \times 2$ ANOVA was used. The main effects studied were participants (girls vs. boys) and group (assessment vs reassessment) and correlations between variables were verified using the Spearman correlation.

\section{Results}

A total of 99 children were evaluated and 51 were girls $(51.5 \%)$. In relation to anthropometric data, there were statistically significant differences between assessment (preschool) and reassessment (school) for all variables ( $p$ $<0.001)$, except for $\mathrm{Z}$ score results $(\mathrm{p}>0.05)$. However, no significant difference between girls' and boys' body mass was found. Sample characteristics are reported in Table 1.
Table 1. Sample characteristics on assessment (preschool) and reassessment (school).

\begin{tabular}{|c|c|c|c|c|c|}
\hline & \multicolumn{2}{|c|}{ Preschool $(n=99)$} & \multicolumn{2}{|c|}{ School $(n=99)$} & \multirow[t]{2}{*}{$\mathbf{p}$} \\
\hline & Median & IQ [25-75] & Median & IQ [25-75] & \\
\hline $\begin{array}{l}\text { Age } \\
\text { (years) }\end{array}$ & 6 & {$[5-6]$} & 9 & {$[9-10]$} & $<0.001$ \\
\hline $\begin{array}{l}\text { Weight } \\
(\mathrm{kg})\end{array}$ & 23 & {$[21-27]$} & 40 & {$[32-47]$} & $<0.001$ \\
\hline $\begin{array}{l}\text { Height } \\
(\mathrm{cm})\end{array}$ & 1.19 & {$[1.16-1.23]$} & 1.43 & {$[1.37-1.48]$} & $<0.001$ \\
\hline Z Score & 0.83 & {$[-0.07-1.99]$} & 1.09 & {$[-0.23-2.24]$} & 0.319 \\
\hline
\end{tabular}

The postural variables evaluated by photogrammetry are reported in Table 2, which were analyzed using four angles and the linear distance in the sagittal plane. The variables analyzed between assessment (preschool) and reassessment (school) showed significant differences for SA and FHD $(\mathrm{p}<0.03)$, demonstrating that in reassessment children have an average SA and a higher FHD than in the assessment.

Table 2. Postural variables analyzed in sagittal plane in assessment (preschool) and reassessment (school).

\begin{tabular}{|c|c|c|c|c|c|}
\hline & Preschool $(n=99)$ & CI $95 \%$ & School $(n=99)$ & CI 95\% & $\mathbf{p}$ \\
\hline $\mathrm{SHA}^{\mathrm{o}}$ & 17.42 & $19.02-15.81$ & 17.06 & $29.17-4.95$ & 0.954 \\
\hline $\mathrm{CA}^{\mathrm{O}}$ & 41.62 & $40.12-43.12$ & 42.10 & $41.08-43.11$ & 0.558 \\
\hline $\mathrm{SA}^{\circ}$ & 32.79 & $30.49-35.09$ & 35.84 & $33.53-38.15$ & $0.026^{*}$ \\
\hline FHD (cm) & 8.40 & $8.07-8.73$ & 11.23 & $10.94-11.52$ & $<0.001 *$ \\
\hline
\end{tabular}

SHA - Sagittal head angle; CA - Cervical angle; SA - Shoulder angle;

FHD - Forward head distance; $\mathrm{CI}$ - Confidence interval; ${ }^{\circ}$ data in angle.

${ }^{*}$ Significant difference $(\mathrm{p}<0.05)$.

Table 3 shows the results of postural variables for girls and boys at both times (assessment and reassessment). At reassessment, girls showed significant differences only in the FHD variable $(\mathrm{p}<0.001)$; while the boys presented significant differences for SHA, SA and FHD variables $(\mathrm{p}<0.04)$. For the
CA variable, no significant differences were found for both groups (girls and boys). For multiple comparisons, no significant differences were found between the variables for girls and boys $(\mathrm{F}=.053-2.54, \mathrm{p}>0.05)$.

Table 3. Results of postural variables analyzed in both moments - assessment and reassessment for girl and boy.

\begin{tabular}{|c|c|c|c|c|c|c|}
\hline & & $\begin{array}{l}\text { Preschool } \\
(n=99)\end{array}$ & CI 95\% & $\begin{array}{l}\text { School } \\
(n=99)\end{array}$ & CI 95\% & $\mathbf{p}$ \\
\hline \multirow[t]{2}{*}{$\mathrm{SHA}^{\mathrm{O}}$} & Girl & 16.94 & $19.16-14.73$ & 21.84 & $24.10-19.59$ & 0.563 \\
\hline & Boy & 17.92 & $20.33-15.51$ & 24.48 & $26.92-22.04$ & $<0.001^{*}$ \\
\hline \multirow[t]{2}{*}{$\mathrm{CA}^{\mathrm{O}}$} & Girl & 41.28 & $39.02-43.53$ & 41.60 & $40.15-43.06$ & 0.777 \\
\hline & Boy & 41.98 & $39.94-44.03$ & 42.62 & $41.17-44.08$ & 0.584 \\
\hline \multirow[t]{2}{*}{$\mathrm{SA}^{\mathrm{O}}$} & Girl & 33.86 & $30.87-36.86$ & 36.10 & $33.23-38.97$ & 0.261 \\
\hline & Boy & 31.66 & $28.06-35.25$ & 35.57 & $31.80-39.33$ & $0.039 *$ \\
\hline \multirow[t]{2}{*}{ FHD (cm) } & Girl & 8.34 & $7.86-8.82$ & 11.40 & $10.96-11.85$ & $<0.001^{*}$ \\
\hline & Boy & 8.46 & $7.98-8.94$ & 11.04 & $10.67-11.41$ & $<0.001 *$ \\
\hline
\end{tabular}

SHA - Sagittal head angle. CA - Cervical angle. SA - Shoulder angle. FHD - Forward head distance. CI - confidence interval; ${ }^{\circ}$ data in angle; * Significant Difference $(p<0.05)$. 
Spearman correlation demonstrated that the forward head distance variable had a positive correlation with children's body mass in the reassessment $(\mathrm{rho}=0.595 ; \mathrm{p}<0.001)$; for all other correlations no important relation was found among variables $(\mathrm{rho}=0.076-0.184 ; \mathrm{p}>0.05)$.

\section{Discussion}

In the present study, certain variables (angular and linear) were selected to determine the head, cervical spine and shoulder position in the sagittal plane and thus to characterize children's posture in the preschool and school periods. Significant differences were observed for head, cervical and shoulder alignment between these two periods of assessment, demonstrating postural changes with the growth and development of the children (confirming our hypothesis).

Head positioning was verified by several variables, but only for FHD, in the proposed initial alignment, was a difference observed between preschool and school periods. An increased forward head distance was observed at school age, which indicates a forward positioning (forward head). With forward head, it is possible to observe disuse of the deep cervical flexor muscle and dominance of the superficial cervical flexor, such as the sternocleidomastoid muscle (SCM), tonic contraction of the SCM, sustained cervical flexion movements and shortening of this muscle ${ }^{23}$. The difference found in head positioning between preschool and school age can be explained as normal postural alteration from musculoskeletal maturation but can be aggravated by the weight of schoolchildren's backpacks ${ }^{6}$ and daily postural habits such as long periods of sitting in an inappropriate position during classes and activities at home, which produce inappropriate head, shoulder and spinal posture ${ }^{24,25}$.

Analysis of the shoulder angle variable showed a difference between the two periods (preschool and school), where shoulder protrusion was observed in the preschool children. Ruivo, Pezarat-Correia, Carita ${ }^{21}$ considered in their study that those who had a shoulder angle less than $52^{\circ}$ had shoulder protrusion. Therefore, the present study provides evidence of forward shoulder for these children, independent of age, but with a worse position in the preschool period (approximately $33^{\circ}$ ). The higher incidence in children with protracted shoulders is normal during the growth and development period, which should decrease after 10 years old ${ }^{26}$. Lafond, Descarreaux, Normand, Harrison ${ }^{27}$ evaluated children 4-12 years old and observed a tendency towards forward head and shoulder displacement according to the child's development. These postural modifications are the result of normal musculoskeletal maturation between childhood and adolescence that could be an adaptation process for adequate sagittal balance, but inappropriate postural habits may favor or even worsen this posture ${ }^{26}$.

The comparison of boys' and girls' posture at assessment and reassessment showed some differences in relation to head, cervical and shoulder positioning only within the group. At reassessment, girls showed differences only in the FHD variable, whileboys presented differences for SHA, SA and FHD variables. On the other hand, in this study, the results for comparison among girls and boys were similar for all variables. Shaheen \& Basuodan ${ }^{28}$ compared head position in children of both sexes between 7 and 9 years old and they observed a significant difference in posture, with girls presenting greater forward head than boys. However, another study corroborate with our finding that there were no differences between the sexes regarding some postural angles (ie trunk, cervical spinal, head) among children from 5 to 12 years old ${ }^{29}$.

The FHD variable showed a positive correlation in reassessment in relation to children's body mass. Therefore, the greater the child's body mass, the greater the value of the forward head distance variable, indicating forward head and a worse postural pattern. Silva, Rodacki, Brandalize, Lopes, Bento, Leite $^{30}$ in their study evaluated posture using photogrammetry in 33 children from 9-17 years old, obese and non-obese, and they observed that obese children presented a higher frequency of forward head. Being overweight, more than metabolic changes, causes changes in body posture and postural control, because the presence of fat concentration in the abdominal area promotes a forward movement of the center of gravity, resulting in many postural changes, such as an increase of cervical lordosis and forward head as a way to recover body balance ${ }^{31,32}$.

Postural changes such as protracted shoulder and forward head are becoming common among children and adolescents, which may persist and cause pain in adulthood ${ }^{21}$. Postural deviations presented in this age group may have been a consequence of natural physiological changes of growth and development $t^{27}$. Postural changes from 7 to 12 years old occur in order to find a balance compatible with new body proportions acquired by growth. Ruivo, Pezarat-Correia, Carita ${ }^{21}$ discuss in their study that possible causes found for postural changes are incorrect use of backpacks, school furniture, biopsychosocial factors such as depression and stress, a higher amount of time in a seated posture and an incorrect body positioning during school time or at home. Finally, daily health habits, both at home or at school, could support the appearance or worsening of postural asymmetry in the sagittal plane.

The number of children who participated, which was based on a convenience sample and not on a representative population sample, could be considered a limitation of the study. The sitting time, weight of schoolchildren's backpacks and physical activity were not evaluated. The lack of standardization of some measurements of photogrammetry can also be stated as one of the study's limitations, since there are no studies with standardized measures to help compare postural changes and assist discussions on findings.

Practical implications of this study suggest alerting parents and teachers to pay attention to the posture of children not only in the school phase, but also in the preschool stage. Orienting children's lifestyle and posture habits is important so that negative effects on posture do not occur during the growth and development period and thus carry over into adulthood. Therefore, parents should be aware of children's posture, and health and education professionals should be involved in screening and prevention programs in order to develop healthy habits, especially those related to body positioning. 


\section{Conclusion}

Our results showed that the head, cervical spine and shoulder posture of children in two periods, assessment (preschool) and reassessment (school), suffered postural changes, mostly forward head and protracted shoulder.

Early follow-up of body posture in childhood should be encouraged and guided, seeking to minimize further problems. In fact, it is important to emphasize that care and guidance should be practiced early in children, suggesting that health policies could be implemented in this population.

\section{References}

1. Magee DJ. Orthopedic physical assessment. Saunders, Elsevier Health Sciences, 2014.

2. Kendall FP, McCreary EK, Provance P. Muscle testing and function. Baltimore, 1993.

3. Santos A. Diagnostico clinico postural um guia pratico. Summus editorial, 2001.

4. Wyszyńska J, Podgórska-Bednarz J, Drzał-Grabiec J, Rachwał M, Baran J, Czenczek-Lewandowska E, et al. Analysis of relationship between the body mass composition and physical activity with body posture in children. BioMed Res Int. 2016;(2016).

5. Straker LM, O'sullivan PB, Smith A, Perry M. Computer use and habitual spinal posture in australian adolescents. Public Health Rep. 2007;122(5):634-643.

6. Kim M, Yi C, Kwon O, Cho S, Yoo W. Changes in neck muscle electromyography and forward head posture of children when carrying schoolbags. Ergonomics. 2008;51(6):890-901.

7. Brzęk A, Dworrak T, Strauss M, Sanchis-Gomar F, Sabbah I, Dworrak B, et al. The weight of pupils' schoolbags in early school age and its influence on body posture. BMC musculoskelet disord. 2017;18(1):117.

8. Azabagic S, Spahic R, Pranjic N, Mulic M. Epidemiology of musculoskeletal disorders in primary school children in bosnia and herzegovina. Mater Sociomed. 2016;28(3):164-67.

9. Foehr UG, Rideout V, Roberts DF. Generation M: Media in the lives of 8-18 year-olds. . 2005.

10. Prado DBAL, Beresoski CM, Camargo MZ, Fernandes KBP, Siqueira CPCM, Fujisawa DS. Sinais precoces de escoliose em crianças pré-escolares. Fisioter Pesq. 2015;22(1):69-75.

11. Resolução N. 466 do conselho nacional de saúde, de 12 de dezembro de 2012 (BR). Aprova as diretrizes e normas regulamentadoras de pesquisas envolvendo seres humanos. Diário Oficial da União. 2013;13.

12. de Onis M, Onyango AW, Borghi E, Siyam A, Nishida C, Siekmann J. Development of a WHO growth reference for school-aged children and adolescents. Bulletin of the World Health Organization. 2007; 85:660-7.
13. Araújo F, Severo M, Alegrete N, Howe L, Lucas R. Defining patterns of sagittal standing posture in school-aged girls and boys. Phys Ther. 2017;97(2):258-267.

14. van Niekerk S, Louw Q, Vaughan C, Grimmer-Somers $\mathrm{K}$, Schreve K. Photographic measurement of upper-body sitting posture of high school students: A reliability and validity study. BMC musculoskelet disord. 2008;9(1):113.

15. Furlanetto TS, Candotti CT, Comerlato T, Loss JF. Validating a postural evaluation method developed using a digital image-based postural assessment (DIPA) software. Comput Methods Programs Biomed. 2012;108(1):203-212.

16. Ferreira EAG, Duarte M, Maldonado EP, Burke TN, Marques AP. Postural assessment software (PAS/SAPO): Validation and reliabiliy. Clinics. 2010;65(7):675-681.

17. McEvoy MP, Grimmer K. Reliability of upright posture measurements in primary school children. BMC musculoskelet disord. 2005;6(1):35.

18. Perry M, Smith A, Straker L, Coleman J, O'Sullivan P. Reliability of sagittal photographic spinal posture assessment in adolescents. Advanc Physiother. 2008;10(2):66-75.

19. Nam SH, Son SM, Kwon JW, Lee NK. The intra-and inter-rater reliabilities of the forward head posture assessment of normal healthy subjects. J Phys Ther Sci. 2013;25(6):737-739.

20. Souza JA, Pasinato F, Basso D, Corrêa ECR, da Silva, Ana Maria Toniolo. Biophotogrammetry: Reliability of measurements obtained with a posture assessment software (SAPO). Rev Bras Cineantropom Desempenho Hum. 2011;13(4):299-305.

21. Ruivo RM, Pezarat-Correia P, Carita AI. Intrarater and interrater reliability of photographic measurement of upper-body standing posture of adolescents. J Manipulative Physiol Ther. 2015;38(1):74-80.

22. Guan X, Fan G, Wu X, Zeng Y, Su H, Gu G, et al. Photographic measurement of head and cervical posture when viewing mobile phone: A pilot study. Eur Spine J. 2015;24(12):2892-2898.

23. Bokaee F, Rezasoltani A, Manshadi FD, Naimi SS, Baghban AA, Azimi H. Comparison of cervical muscle thickness between asymptomatic women with and without forward head posture. Braz J Phys Ther. 2017;21(3):206-211.

24. Park H, Kim Y, Seok S, Lee S. The effect of complex training on the children with all of the deformities including forward head, rounded shoulder posture, and lumbar lordosis. J Exerc Rehabil. 2014;10(3):172-175.

25. van Gent C, Dols JJ, de Rover CM, Hira Sing RA, de Vet HC. The weight of schoolbags and the occurrence of neck, shoulder, and back pain in young adolescents. Spine (Phila Pa 1976). 2003;28(9):916-921.

26. Santos CIS, Cunha ABN, Braga VP, Saad IAB, Ribeiro MAGO, Conte PBM, et al. Ocorrência de desvios posturais em escolares do ensino público fundamental de Jaguariúna. Rev Paul Pediatr. 2009;21(1):74-80.

27. Lafond D, Descarreaux M, Normand MC, Harrison DE. Postural development in school children: A cross-sectional study. Chiropr Osteopat. 2007;15(1):1. 
28. Shaheen AA, Basuodan RM. Quantitative assessment of head posture of young adults based on lateral view photographs. J Phys Ther Sci. 2012;24(5):391-394.

29. McEvoy MP, Grimmer K. Reliability of upright posture measurements in primary school children. BMC musculoskelet disord. 2005;6(1):35.

30. Silva LRD, Rodacki ALF, Brandalize M, Lopes MFA, Bento PCB, Leite N. Postural changes in obese and nonobese children and adolescents. Rev Bras Cineantropom Desempenho Hum. 2011;13(6):448-454.

31. Camargo CS, Pereira K. Progression of anthropometric variables, posture and balance of obese and overweight children. ConScientiae Saúde. 2012;11(2):256.

32. Kussuki M, Joao S, Cunha A. Postural characterization of obese children spine between 7 and 10 years old. Fisioterap Mov. 2007;20(1):77-84.

\section{Corresponding author}

Mariana Zingari Camargo

Amador Bueno, 250. 86010-620 Londrina, PR,Brazil

Email: marianazcamargo@hotmail.com

Manuscript received on June 16, 2017

Manuscript accepted on September 08, 2017

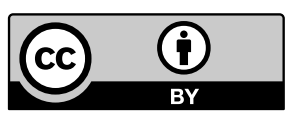

Motriz. The Journal of Physical Education. UNESP. Rio Claro, SP, Brazil - eISSN: 1980-6574 - under a license Creative Commons - Version 3.0 